\title{
Community mental health nursing training package on body image quality among mental disorders patients
}

\author{
Ibrahim Rahmat ${ }^{1}$, Mohammad Hakimi ${ }^{2}$, Soewadi $^{3}$ \\ ${ }^{1}$ Mental Health and Community Department, School of Nursing, Faculty of Medicine, Public Health, and Nursing, \\ Gadjah Mada University, Indonesia \\ ${ }^{2}$ Department of Obstetrics and Gynecology, School of Medicine, Faculty of Medicine, Public Health and Nursing, \\ Gadjah Mada University, Indonesia \\ ${ }^{3}$ Department of Psychiatry, School of Medicine, Faculty of Medicine, Public Health and Nursing, \\ Gadjah Mada University, Indonesia
}

\begin{tabular}{|c|c|}
\hline Article Info & ABSTRACT \\
\hline Article history: & Mental health disorder could affect the physical, mental, social, and spiritual \\
\hline Received Jun 9, 2020 & $\begin{array}{l}\text { problems, leading to psychosocial issues such as body-image problem. } \\
\text { Body-image is a basic need of human being to fulfill and therefore, }\end{array}$ \\
\hline Revised Aug 20, 2020 & the multidisciplinary team; physicians, nurses, and family should have \\
\hline Accepted Sep 12, 2020 & $\begin{array}{l}\text { adequate knowledge on the body-image. Increasing knowledge by training } \\
\text { the nurses and community health volunteers can be performed to address }\end{array}$ \\
\hline Keywords: & $\begin{array}{l}\text { body-1mage issues in patients with mental disorders among the community. } \\
\text { This study held to identify the effects of community mental health nursing }\end{array}$ \\
\hline Body image & $(\mathrm{CMHN})$ and Self-Concept Assessment Guidelines training on nurse and \\
\hline Community mental health & $\begin{array}{l}\text { community health volunteer in increasing the body-image quality of patients } \\
\text { with mental disorders. This study used pre and post quasi experimental test }\end{array}$ \\
\hline nursing & with nonequivalent control group design. By comparing the pre-test and post- \\
\hline Mental disorder & test scores, nurse's and community health volunteer's knowledge were \\
\hline Public health & increasing after being given training. Data of body image was collected from \\
\hline Training & $\begin{array}{l}129 \text { patients with mental disorder (treatment group of } 69 \text { and control group } \\
\text { of } 60 \text { ) as volunteers. After the intervention, treatment group ( } \mathrm{p}=0.033 \text { ) and } \\
\text { control group }(\mathrm{p}=0.075) \text { show that significant increase in the quality of } \\
\text { body-image only applies to the treatment group. Providing training on } \\
\text { CMHN was effective to improve body-image quality of patients with mental } \\
\text { disorders. }\end{array}$ \\
\hline
\end{tabular}

This is an open access article under the CC BY-SA license.

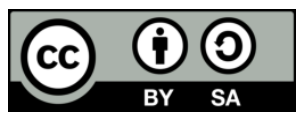

\section{Corresponding Author:}

Ibrahim Rahmat,

Mental Health and Community Department,

School of Nursing, Faculty of Medicine, Public Health and Nursing,

Gadjah Mada University,

Yogyakarta 55281 Indonesia

Email: Ibrahim.rahmat@ugm.ac.id

\section{INTRODUCTION}

Well-being is not only a matter of physical health, but also mental health as in intrapersonal, interpersonal, and social life. The concept of mental health is a condition where individuals feel good about themselves, are able to maintain intrapersonal relationships, are aware of each other's abilities, can handle stress normally in life, can work productively, be useful and contribute to the community [1]. According to Videbeck [2] mental health is a state of healthy in emotion, psychological, social aspects reflected in satisfying interpersonal relationship, effective behavior, positive self-concept and emotionally stable. 
People with Mental Health Disorders are those who have problems in thinking, behaving, and feeling manifested in a set of symptoms and/or changes in significant behavior, and may cause distress and impairment in performing their functions as human being [3]. One of the factors causing someone to suffer from mental illness is the psychosocial stressor [4]. However, not all people are capable to adapt and handle it. Therefore, complaints in mental state may arise such as psychological distress, over anxiety, to depression [5].

Any changes in health can become a stressor affecting the individual self-concept [6]. Body-image, one of self-concept component, is how someone perceives the size, appearance, parts of body and their functions [7]. Positive and appropriate body-image is one of the characteristics of healthy personality [6]. Research shows that a good body-image can improve one's quality of life [8,9].

Mental health problems can be caused by natural disasters such as earthquake in Bantul, DIY, Indonesia. Natural disasters have an impact on both physical and mental state especially psychosocial related problems [10]. The physical impact results in death, mild to severe disability, and disability for life. Meanwhile, the impact of the mental problem causes a person to feel lost, do not want to get along, feel meaningless in his life, and think that it is better to die than survive. Someone with mental problems feels difficult to accept reality. The symptoms mentioned above are psychosocial problems and a mental disorder [11, 12].

Data published by the Health Ministry at 2009 [13], in regular meeting at 19 public health centers in Bantul Regency shows that the number of patients treated independently was 543 people, and those treated in hospitals were 62 people. This phenomenon of mental patients in the community comes from returned patients from mental hospitals or public hospitals after declared stable enough. Unfortunately, most families and communities are not prepared to giving care to patients at home $[14,15]$. Mental health problems in the community require approaches and strategies involving community supervised health workers. Community mental health nursing $(\mathrm{CMHN})$ is one approach to nursing services to patients carried out directly on patients, and families at home by public health center nurses assisted by other health workers $[16,17]$.

In meeting the psychosocial needs of mental patients, nurses still follow the patterns and daily habits for there are no permanent procedures in the community on an ongoing basis. To handle this phenomenon, professional nurses are needed, which can be achieved by giving training [18]. Training to improve skills and knowledge has been implemented across a wide range of disciplines including medicine, mental health, nursing, social work and allied professions. It has been said that active strategies such as training is more effective [19]. The purpose of this study was to analyze the effects of providing basic course community mental health nursing (BC-CMHN), self-concept assessment guideline (SCAG), cognitive behavior therapy (CBT), and thought stopping therapy (TST) training for nurses, and intermediate course community mental health nursing (IC-CMHN) training for community health volunteers (CHVs) to the body image quality of patient with mental health disorders.

\section{RESEARCH METHOD}

This was a quantitative quasi experimental research, with research design nonequivalent with the control group pretest and posttest design. The research was conducted in 10 community health centers in Bantul Regency and it was performed from November 2012 to February 2013. The population was patients with mental disorders from mild to severe at maintenance and health promotion treatment. The size of the sample used by the researcher used Slovin theory [20].

The sample size used by the researcher was e value: $20 \%(0.02)$ from the total population in 27 community health centers. Based on the calculation, it was obtained: 49.29 rounded to $50 \pm 10$ respondents, and therefore, it resulted in 60-70 respondents. The number of mental disorder patients of each community health center was 100-150 patients in average; 10-15 mental disorder patients were taken from each community health centers as volunteer. The samples who met the inclusion criteria for treatment group from five community health centers were 69 patients with mental disorders from mild to severe at maintenance and health promotion treatment and for the control group were 60 respondents, meaning that it was in line with the calculation of sample size. This research was reviewed and approved by the Health Research Ethics Committee of Faculty of Medicine, Public Health, and Nursing, Gadjah Mada University, Indonesia, number KE/FK/590/EC.

The community health centers that involved in this study were 10 health centers in total, which divided to treatment group (five community health centers) and control group (five community health centers). This research was divided into several stages. Training for the nurses and CHVs in community health centers were conducted in the community health centers included in the treatment group. The nurses received training on BC-CMHN in which the materials were obtained from Keliat [21], training on Intervention of cognitive behavior therapy (CBT) and Thought Stopping Therapy, and training on self-concept study using the Self-Concept Assessment Guidelines [22]. The training on study and treatment skills was assisted by a licensed CMHN team. The CHVs in the relevant community health centers received training on IC-CMHN. 
While for the control group (five community health centers), the nurses were provided with reading assignment on BC-CMHN and Self-Concept Assessment Guidelines which was the same material given to the treatment group, but without CBT and TST materials in order that the control group will give treatment as usual (TAU) to the respondent in the control group. Meanwhile the CHVs were provided with module to read on IC-CMHN with the same material as in the training for the treatment group.For knowledge evaluation, pretest and posttest were conducted in both groups, while the evaluation on the intervention skill and selfconcept assessment was conducted through interview with simulation family and patient (using role play).

Third, after the nurses were said to be competent, then intervention to the respondents $(n=129)$ according to each group (intervention $n=69$, control $n=60$ ) was carried out. Before given the treatment, a pretest for patients was carried out. The intervention was conducted for 1 month in 3 meetings. Afterward, the evaluation was performed using posttest to assess the body-image of the respondents. The research instrument used to assess body image quality was a questionnaire regarding body image quality consisted of 8 items and validated using the correlation technique formula Product moment and reliability test using Alpha Cronbach for the instrument with interval data types. It was obtained 0.34-0.93 for validity test, while the reliability test was 0.91 , indicated the items are valid and reliable. This research used $t$-test, but the results of $t$-test was abnormal, so it used the non-parametric statistic test, which was Wilcoxon match pairs test.

\section{RESULTS AND DISCUSSION}

\subsection{Trainings on nurse competence achievement and mental disorder patients}

The results of training given for the treatment and control groups were the pretest score with a mean value of 39.6 for the treatment group and 36.6 for the control group with a difference of 3.0 and the posttest score with a mean value of 47.8 for the treatment group and 40.3 for the control group with a difference of 7.5 points, means that both treatment and control group experience an increase, even though the treatment group has a higher increase. There is a difference of 5.2 points in the competence achievement scores between the treatment group and the control group. Results of CMHN nurses competence achievement score $(\mathrm{n}=10)$ as shown in Table 1.

\begin{tabular}{|c|c|c|c|c|c|}
\hline \multirow{2}{*}{ No } & \multirow{2}{*}{ Nurse's Name } & \multicolumn{2}{|c|}{ Score } & \multirow{2}{*}{ Mean score } & \multirow{2}{*}{ Improvement score } \\
\hline & & Pre-test & Post-test & & \\
\hline \multirow[t]{6}{*}{$\mathrm{A}$} & Treatment Group & & & & \\
\hline & 1. Nurse 1 & 46 & 56 & 51 & 10 \\
\hline & 2. Nurse 2 & 31 & 57 & 44 & 26 \\
\hline & 3. Nurse 3 & 51 & 55 & 53 & 4 \\
\hline & 4. Nurse 4 & 33 & 55 & 44 & 22 \\
\hline & 5. Nurse 5 & 37 & 58 & 47 & 21 \\
\hline \multicolumn{2}{|c|}{ Total Score /Mean } & $198 / 39.6$ & $281 / 56.2$ & $239 / 47.8$ & $83 / 16.6$ \\
\hline \multirow[t]{6}{*}{ B } & Control Group & & & & \\
\hline & 1. Nurse 6 & 34 & 41 & 37.5 & 7 \\
\hline & 2. Nurse 7 & 35 & 50 & 42.5 & 15 \\
\hline & 3. Nurse 8 & 32 & 53 & 42.5 & 21 \\
\hline & 4. Nurse 9 & 38 & 47 & 42.5 & 9 \\
\hline & 5. Nurse 10 & 44 & 49 & 46.5 & 5 \\
\hline \multicolumn{2}{|c|}{ Total Score /Mean } & $183 / 36.6$ & $240 / 48$ & $201.5 / 40.3$ & $57 / 11.4$ \\
\hline
\end{tabular}

The trained nurses continued to educate patients with mental health disorder. The recruited patients were mostly in maintenance and health promotion phases. The information of characteristics for mental disorder patients or volunteers $(n=129)$ was available in Table 2. Total patients who involved in our study were 69 and 60 patients for intervention and control group, respectively. Most males patients participated in our study for both intervention and control gorup. For intervention group, the major participants came from Jetis II $(n=17)$ while the Imogiri I and Jetis I $(n=15)$ dominated in control group.

\subsection{CMHN training on community health volunteer}

Evaluation on the training used the same questions in pre and post-test with a total of 17 items. From the 17 items, in the pre-test session, it was obtained a mean of 7.9 points, while in the post-test it was obtained a mean of 12.6 points. So, there is an increase of 4.7 points. Therefore, it can be concluded that the training improves the knowledge of mental health volunteers. The mental health volunteers who received the training were assigned to detect and identify the healthy family, family at risk or with disorders. 
Moreover, the researcher also evaluated the comparison value between the pre-test and post-test scores which resulted as follows: mean of pre-test answering correctly was 4.92 from 10 items and the mean of post-test was 7.11 from 10 items so there is an increase of $44.4 \%$. Based on the evaluation of pretest and posttest scores of the nurses and CHVs, it can be concluded that CMHN trainings can improve the knowledge of nurses and CHVs. It is in line with some literature that said trainings can strengthen the competence of nurses in terms of knowledge, skill and even daily habit and it is applicable to treatment activities [18, 19]. The CMHN training that being held gathered some nurses with the same concern on community mental health which brings the widest pool of relevant knowledge. By following the CMHN training, the nurses and CHVs in treatment group interacting with their peer which-through exchanges-developing their communication skills and foster learning, enhancing theirs professional knowledge [23]. But the increase in the control group, although not as progressive as in treatment group, can't be ignored. Some study reveal that using module as a mean of education can also give meaningful input [19, 24]. And considering some nurse's job burden it's preferred to give module to read [25]. The difference in knowledge improvement-greater in treatment group- may because of lack of feedback in control group [23].

Since the training process aims at improving the knowledge of nurses, it is expected that it can reach the goals of mental health nursing in the community. Trainings offer specific knowledge and skill in nursing and it can be defined to use in providing mental health nursing in the community nowadays. It is the most effective if using interpersonal approach which is the interaction between nurse and family, nurse and patient, and nurse with patient and family. It is in accordance with the research conducted by Price and Reichert [26] who suggest that trainings for nurse can help improve the service quality provided for the patients.

\begin{tabular}{|c|c|c|c|c|}
\hline \multirow{2}{*}{ No } & \multirow{2}{*}{$\begin{array}{c}\text { Community health } \\
\text { center }\end{array}$} & \multicolumn{2}{|c|}{$\mathrm{n}$} & \multirow{2}{*}{ Total } \\
\hline & & Male & Female & \\
\hline \multirow[t]{7}{*}{$\mathrm{A}$} & Intervention group & & & \\
\hline & 1. Pandak II & 7 & 8 & 15 \\
\hline & 2. Imogiri II & 8 & 7 & 15 \\
\hline & 3. Kasihan II & 5 & 6 & 11 \\
\hline & 4. Bambanglipuro & 4 & 7 & 11 \\
\hline & 5. Jenis II & 11 & 6 & 17 \\
\hline & Subtotal & 35 & 34 & 69 \\
\hline \multirow[t]{7}{*}{ B } & Control group & & & \\
\hline & 1. Imogiri I & 10 & 5 & 15 \\
\hline & 2. Kasihan I & 6 & 4 & 10 \\
\hline & 3. Jetis I & 7 & 8 & 15 \\
\hline & 4. Kasihan I & 5 & 5 & 10 \\
\hline & 5. Sewon & 3 & 7 & 10 \\
\hline & Subtotal & 31 & 29 & 60 \\
\hline
\end{tabular}

\subsection{Body image}

Body-image is how someone perceived his body regarding the physical appearance that distinguishes him from others [7]. The analysis result can be seen in Table 3. The analysis results of mean difference of body-image components of the control group in pretest and posttest shows no significant difference ( $p>0.05)$. Mean difference in pretest and posttest of the treatment group has a significant difference $(p<0.05)$. Mean increase after intervention is $23.65 \pm 3.77$ to $24.55 \pm 3.53$. The mean result of pretest and posttest on body-image shows a significant difference statistically $(\mathrm{p}<0.05)$.

Table 3. Mean differences of body-image in intervention and control group $(n=129)$

\begin{tabular}{ccccccc}
\hline Body image score & \multicolumn{4}{c}{ Treatment } & \multicolumn{3}{c}{ Total of body-image } \\
& \multicolumn{2}{c}{ Intervention } & Control & p & \\
& Mean \pm SD & Median & Mean \pm SD & Median & & \\
\hline Pre-test & $23.65 \pm 3.77$ & 24 & $23.42 \pm 3.67$ & 23.50 & $23.54 \pm 3.71$ & 0.866 \\
Post-test & $24.55 \pm 3.53$ & 24 & $24.10 \pm 3.16$ & 24 & $24.34 \pm 3.36$ & 0.590 \\
p-value & $0.033^{*}$ & \multicolumn{3}{c}{0.075} & & $0.006^{*}$ \\
\hline
\end{tabular}

The analysis of body-image component with the chart shows that there was an increase in median in treatment group as well as in the control group although statistically, there was a more significant increase in the mean test of the treatment group on body-image. For the control group, there is no significant difference $p>0.05$, even though all mean increased as shown in Table 2. The overall mean of pre and posttest on patient's body-image in treatment group shows a significant difference with $\mathrm{p}$-value $=0.006(\mathrm{p}<0.05)$, 
meaning that CMHN training that has been given to nurses and health volunteers in treatment group affects the improvement of patient's body-image. An explanation on this result is communication skills are more likely improved with interactive, face-to-face training, hence more likely to improve patient outcomes that can be linked to availability of professional knowledge [23]. In the training, nurses and CHVs communicating with each other's, ensuring exchange of more information and feedback, and when the knowledge applied in practice, the care given to patient becomes more consistent thus improving patient's outcome (in this case, patient's body image) [23]. The trainings also gives the nurses and volunteers chance to interact with the instructors thus giving more room to process and discuss information [27].

Someone has his own perception of body-image, including his body image, body image he desires, and people's view on his body. With the three images, someone evaluates himself and forming judgment on his body-image [7,8]. If the perception on his own body-image is positive, he will be satisfied and it can increase his self-esteem. On the other hand, if the perception is negative, it will raise dissatisfaction on the body-image [8]. This negative perception can lead to body-image disorder which is an excessive perception about body shape [28]. This excessive perception is likely to affect activities such as sleeping and healthy diet which are the crucial components in health $[29,30]$. Some people also feel helpless, hopeless, powerless and weak, and possibly have self-harming habits such as anorexia and suicidal tendency [7, 25]. Body-image partly depends on body state. People commonly cannot rapidly adapt to physical changes. Physical changes may be not always included in an ideal body-image, for example someone who lose weight does not consider himself as skinny [6].

The result showed body-image can change in hours, days, weeks, or months, depending on the external stimuli to the body and actual changes in appearance, structure or function [7]. The external stimulus in this study was the intervention performed by the researcher consisting of trainings on IC-CMHN, BC-CMHN, study on self-concept, CBT and TS. Furthermore, Keliat [21] view that one of stressor affecting body-image is medical procedure or treatment. The nurses stated that BC-CMHN training in the treatment group was easily understandable since it has been conducted previously during the rehabilitation after earthquake. At first, the body image assessment using SCAG, CBT and TST training were hard to follow because the materials were not familiar and new for the nurses in the community health center. However, after three days training, the participants know the importance of the study concept to implement, as there are a lot of information to reveal from the patients, especially related to self-perception of the patient, such as low self-esteem, uselessness, disappointment with the reality and feeling ostracized by the society.

IC-CMHN training for mental health volunteers, and BC-CMHN, study on self-concept, CBT and TST training for nurses are performed with a well-prepared plan to achieve good results. Training needs to be planned because it can affect the results of the training itself [31], that when a training is not designed as an opportunity to improve a specific work performance, the nurses tend to ignore the importance of training and only a few changes can be seen on their work performance [19]. It also applies to nurses or CHVs in this study, stated that they will feel bored with the training if it does not offer additional values to them, not to mention if the training has fee they have to pay.

\section{CONCLUSION}

This research concluded that CMHN training, SCAG training, CBT and TST training for nurses and CHVs could improve the quality of body-image among the patients with mental disorders. Based on the discussion above, it is recommended that the authoritative policy makers i.e. the regional officials to understand the importance of CMHN program so they can allocate some part of the Local Government Budget for CMHN training. For the community health center, it is suggested to make the best use and maintain the training that had been conducted by the researcher, so it can support the programs of the community health center, especially in the management of patients with mental disorders in the community.

\section{REFERENCES}

[1] World Health Organization, mhGAP community toolkit: field test version. Geneva: World Health Organization, 2019.

[2] S. L. Videbeck, "Psychiatric mental health nursing," Philadelphia: Wolters Kluwer : Lippincott Williams \& Wilkins, 2011.

[3] P. Tj, "Mental Disorders are Not Real: Using Skepticism and Critical Thinking to Challenge Key Myths in the Science of Mental Health," J. Ment. Disord. Treat., vol. 3, no. 1, 2017. doi: 10.4172/2471-271X.1000140

[4] C. Young, C. Hanson, J. C. Craig, K. Clapham, and A. Williamson, "Psychosocial factors associated with the mental health of indigenous children living in high income countries: a systematic review," Int. J. Equity Health, vol. 16, no. 1, p. 153, Dec. 2017. doi: 10.1186/s12939-017-0652-5

[5] G. Hassan, P. Ventevogel, H. Jefee-Bahloul, A. Barkil-Oteo, and L. J. Kirmayer, "Mental health and psychosocial wellbeing of Syrians affected by armed conflict," Epidemiol. Psychiatr. Sci., vol. 25, no. 2, pp. 129-141, Apr. 2016. doi: $10.1017 /$ S2045796016000044

[6] P. A. Potter, A. G. Perry, P. Stockert, and A. Hall, Fundamentals of Nursing - E-Book. 2016.

Community mental health nursing training package on body image quality of mental... (Ibrahim Rahmat) 
[7] A. Berman, S. J. Snyder, and Geralyn Frandsen, Kozier\&Erb's, "Fundamental of Nursing: Concepts, Process, and Practice," 10th ed. England: Pearson, 2016.

[8] T. Nayir, E. Uskun, M. V. Yürekli, H. Devran, A. Çelik, and R. A. Okyay, "Does Body Image Affect Quality of Life?: A Population Based Study," PLoS One, vol. 11, no. 9, p. e0163290, Sep. 2016. doi: 10.1371/journal.pone.0163290

[9] M. S. Medeiros de Morais et al., "Does body image perception relate to quality of life in middle-aged women?," PLoS One, vol. 12, no. 9, p. e0184031, Sep. 2017, doi: 10.1371/journal.pone.0184031

[10] J. Roudini, H. R. Khankeh, and E. Witruk, "Disaster mental health preparedness in the community: A systematic review study," Health Psychol. Open, vol. 4, no. 1, p. 205510291771130 , Jan. 2017. doi: 10.1177/2055102917711307

[11] M. Maeda, M. Oe, and Y. Suzuki, "Psychosocial effects of the Fukushima disaster and current tasks: Differences between natural and nuclear disasters," J. Natl. Inst. Public Health, vol. 65, no, 1, pp. 50-58, 2018.

[12] U. Martin, "Health after disaster: A perspective of psychological/health reactions to disaster," Cogent Psychol., vol. 2, no. 1, Jun. 2015. doi: 10.1080/23311908.2015.1053741

[13] Yogyakarta Health Ministry, "Regular meeting II: Community Mental Health Nursing (CMHN), Laporan Pelaksanaan Hasil Pelatihan," Yogyakarta Health Ministry, Bantul Regency, Yogyakarta, 2009.

[14] N. Purwanti, Ah. Yusuf, and S. Suprajitno, "Video-Based Disposal Planning by agreeing on a Family Care Center for the Family's Ability to Care for Schizophrenic Clients" (Pengaruh Discharge Planning Berbasis Video dengan Pendekatan Family Center Nursing Terhadap Kemampuan Keluarga Merawat Klien Skizofrenia," Journal Ilmiah Kesehatan, vol. 10, no. 2, pp. 206-2013, 2017.

[15] Raymondalexas Marchira, W. Andan Puspitasari, I. Rochmawati, and S. Mulyani, "Evaluation of primary health workers training program to provide psychoeducation to family caregivers of persons with psychotic disorder," J. Thee Med. Sci. Berk. Ilmu Kedokt., vol. 47, no. 1, pp. 36-42, Mar. 2015. doi: 10.19106/JMedSci004701201505

[16] D. Sines, S. Aldridge-Bent, A. Fanning, P. Farrelly, K. Potter, and J. Wright, "Community and Public Health Nursing," 5th ed. England: Willey Blackwell, 2013.

[17] J. Perry, L. Palmer, P. Thompson, A. Worrall, and R. Chaplin, "Standards for Community-Based Mental Health Services," The Royal Collage of Psychiatrists, England, 2017.

[18] M. Fukada, "Nursing Competency: Definition, Structure and Development," Yonago Acta Med., vol. 61, no. 1, pp. 1-7, 2018. doi: 10.33160/yam.2018.03.001

[19] The Health Foundation, "Evidence scan: Quality Improvement Training for Healthcare Professionals," The Health Foundation, United Kingdom, Foundation Online Publication, Aug. 2012. [Online]. Available: https://www.health.org.uk/sites/default/files/QualityImprovementTrainingForHealthcareProfessionals.pdf

[20] M. S. Dahlan, "Large Sample and Sampling Method in Health Medicine Research (Besar Sampel dan Cara Pengambilan Sampel dalam Penelitian Kedokteran Kesehatan)," 3rd ed. Jakarta: Salemba Medika, 2010.

[21] B. A. Keliat, "Psychosocial nursing management \& mental health cadre: CMHN (intermediate course)," (Manajemen keperawatan psikososial \& kader kesehatan jiwa: CMHN (intermediate course)," Jakarta: EGC, 2011.

[22] R. Ibrahim, "Guidelines for Self Concept Assessment (PPKD), Pedoman Pengkajian Konsep Diri (PPKD)," Yogyakarta: Betha Grafika Yogyakarta, 2015.

[23] K. Garzonis, E. Mann, A. Wyrzykowska, and P. Kanellakis, "Improving Patient Outcomes: Effectively Training Healthcare Staff in Psychological Practice Skills: A Mixed Systematic Literature Review," Eur. J. Psychol., vol. 11, no. 3, pp. 535-556, Aug. 2015, doi: 10.5964/ejop.v11i3.923

[24] S. Tohidi, H. KarimiMoonaghi, A. Shayan, and H. Ahmadinia, "The effect of self-learning module on nursing students' clinical competency: A pilot study," Iran. J. Nurs. Midwifery Res., vol. 24, no. 2, p. 91, 2019. doi: 10.4103/ijnmr.IJNMR_46_17

[25] K. Abbasi, M. Hazrati, N. P. Mohamadi, and A. Rajaeefard, "The effect of learning via module versus lecture teaching methods on the knowledge and practice of oncology nurses about safety standards with cytotoxic drugs in Shiraz University of Medical Sciences," Iran. J. Nurs. Midwifery Res., vol. 18, no. 6, p. 483, Dec. 2013.

[26] S. Price and C. Reichert, "The Importance of Continuing Professional Development to Career Satisfaction and Patient Care: Meeting the Needs of Novice to Mid- to Late-Career Nurses throughout Their Career Span," Adm. Sci., vol. 7, no. 2, p. 17, Jun. 2017. doi: 10.3390/admsci7020017.

[27] J. Bluestone, P. Johnson, J. Fullerton, C. Carr, J. Alderman, and J. BonTempo, "Effective in-service training design and delivery: evidence from an integrative literature review," Hum. Resour. Health, vol. 11, p. 51, 2013, doi: 10.1186/1478-4491-11-51

[28] N. L. Keltner and D. Steele, "Phychiatric Nursing," 7th ed. Missouri: Elsevier Mosby, 2015.

[29] U. Akram, "Sleep associated monitoring on awakening mediates the relationship between cutaneous body image dissatisfaction and insomnia symptoms," Sleep Sci., vol. 10, no. 2, pp. 92-95, 2017, doi: 10.5935/19840063.20170017

[30] A. Devrim, P. Bilgic, and N. Hongu, "Is There Any Relationship Between Body Image Perception, Eating Disorders, and Muscle Dysmorphic Disorders in Male Bodybuilders?," Am. J. Mens Health, vol. 12, no. 5, pp. 1746-1758, Sep. 2018, doi: 10.1177/1557988318786868

[31] P. N. Blanchard and J. Thacker, "Effective Training," 5th ed. London: Pearson, 2013.

Int. J. Public Health Sci, Vol. 9, No. 4, December 2020: 287 - 292 